\title{
Paradigm Shifts in Teaching and Learning at the University of Namibia: Kavango West Region at the Core
}

\author{
Natalia S. Intja, Martha Nahole \\ nreino@unam.na \\ University of Namibia, Rundu Campus, Winhoek 88, Nambia \\ University of Namibia, Rundu Campus, Winhoek 88, Nambia
}

\begin{abstract}
This study evaluated the training program offered by the University of Namibia, Rundu Campus. The aim was to ascertain the contests that education students face in fulfilling their duties in the teaching profession and deduce approaches which the University of Namibia could engage in their teaching and learning to safeguard students' success in their academic life after graduation. The study is qualitative in nature which was conducted through purposive sampling and analysed thematically. The sample consisted of twenty graduates in the years 2011- 2018, three inspectors, subject advisors, Heads of departments and school principals from Kavango West Region participated in the study. Data was collected using semi- structured interviews. The results revealed that a lack of knowledge of the general job description, national standards, code of conduct for teachers and the public act seem to be a challenge. Thus, Unam's curriculum should be designed in such a way that more contact hours are reserved for practical than theory. The article concludes by making recommendations that a closer look at these challenges and approaches may be beneficial to the curriculum reviewers, designers and educators of Unam to confirm successful teacher trainees prior to joining the workforce.
\end{abstract}

Keywords: Paradigm Shifts; University of Namibia; Teaching and Learning

\section{Introduction}

The recent rapid advancement of technologies provides everyone with many new capabilities and, at the same time, changes the ways people live, study, work, and interact with others, as Schwab (2017) signifies that the new industrial revolution with its fusion of technologies across the physical, digital, and biological worlds causes shift not only across all industries, but also towards society, and reshapes governments, institutions, systems of education, and many others. This industrial era requires the University of Namibia's stakeholders to have creative insight, collaborative team work, and adaptively toward culture differences, including intercultural and interpersonal skills (Penprase, 2018). In the framework of paradigm shifts, especially in the teaching and learning context, this circumstance indicates that the University of Namibia have to develop interactive forms of pedagogy and put emphasis on multiple disciplinary and cultural perspectives, in order to cultivate students (human) capacities and skills. 
Xing (2017) notes that today all graduates face a world transformed by technology, in which the Internet, cloud computing, and social media create different opportunities and challenges for formal education systems. As students consider life after graduation, universities are facing questions about their own destiny especially employment. These technologies powered by artificial intelligence are so much transforming the world that social concepts such as "post-work" are more and more defining the present period. This period requires certain skills that are not exactly the same as the skills that were required in the third industrial revolution where information technology was the key driver. These skills are critical thinking, people management, emotional intelligence, judgment, negotiation, cognitive flexibility, as well as knowledge production and management.

Observably, the development of higher education system has gone through the following stages, namely, elite, mass, and post-massification. In the elite stage, higher education has profound origins starting in the 6th century monastic schools and later evolving into the medieval European University beginning in Bologna in 1088 which focused on theology and philosophy, and progressing into the current modern higher education system. In this evolution universities evolved from just being centers of teaching and learning, to include research and thereafter to include service to society. In its early stage, university education was catered for tiny elites. In that time, higher education was intended to mould the minds and characters of the ruling class (Xing, 2017).

Marwala (2015) maintains that in the stage of mass in the late 20th century, the tension between education as a private right or a public good prompted the trend to 'massification', i.e. provide higher education to many people. During this period, the higher education spawned changes in a massive way in terms of many factors such as the size and shape of systems, the curriculum designs, the organisational structures, the pedagogy methodologies, the delivery modes, the research patterns, and the relationship between institutions and other external communities. The main goal of mass higher education was targeting transfer of skills and preparation for a wide variety of technical and economic roles. Whereas, in the post-massification higher education has gradually progressed from the elite phase to mass higher education and then to post-massification stages. Many advanced and some developing economies enjoy the tertiary participation rates of over 50\%. Another characteristic of this trend is internationalisation of both students and staff. According to a report from OECD, with demographic changes, international student mobility is expected to reach 8 million students per year by 2025. South Africa is presently hosting many sub-Saharan students, with much of the remainder studying in European and American countries. Currently, adapting population to rapid social and technological change remains the main goal of many countries, specifically, at the University of Namibia.

It is very important to note that the University of Namibia should respond to the outcry from various schools where its graduates are employed after graduation. According to the school hosts, some education graduates from the University of Namibia seems to be incompetent in subject content delivery, professionalism as well as abiding by the education act and the vows they have made whilst graduating. The researcher's starting point is to investigate the problems that our education graduates from Unam's Rundu Campus experience in the teaching profession and confirm the rumour around the country about education students from the University of Namibia not been fit for the workforce and deduce approaches which the university may employ in its teaching and learning to ensure education students' success in academic life after graduating. 


\section{Theoretical Framework}

The theoretical thrusts reviewed in this article are based on Kirkpatrick's model of evaluating training programs. Kirkpatrick first proposed his approach to evaluation in 1959. The model was extensively reviewed as part of its semi-centennial celebrations (Kirkpatrick \& Kayser-Kirkpatrick, 2014). It consists of four levels of evaluation designed to appraise course training (Table 1). The model is an established and recognised approach which provides a structure and does not require an inordinate amount of time to administer. Although the approach has its critics, and is not the only way to evaluate interventions, the contribution of the Kirkpatrick model in organizations "cannot be underestimated" (Saks \& Haccoun, 2010, p. 332), given its wide use for over 55 years.

The Kirkpatrick model has been employed in higher education settings with varying opinions about its efficacy (see Abdulghani, Shaik, Khamis, Al-Drees, Irshad, Kalil \& Isnani, 2014; Chang \& Chen, 2014; Praslova, 2010; Yardley \& Dornan, 2012). Although Saks and Haccoun (2010) concluded it may not be wellsuited to formative evaluation, and Holton (1996) and Alliger, Tannenbaum, Bennett, Traver \& Shotland (1997) have criticised the hierarchical nature of the approach, these conclusions have not been further substantiated, nor had an impact on its application in industry. Its simplicity and focus, and its systematic approach, mean that it remains one of the most widely used tools for training evaluation. It therefore provides a useful starting point for evaluation of curriculum.

Reaction is Kirkpatrick's first level of evaluation, which behavior change and finally results are the real gains of the evaluation on how the participants living the learning educational program view and rate what was just learnt. Conferring to the model each level is experience perceiving the action (Kirkpatrick, 1998).

\subsection{Justification of Choice}

The Kirkpatrick's model was chosen by the researchers on the basis that the study aimed at ascertaining the challenges that education students face in fulfilling their duties in the teaching profession after training and deduce approaches which the University of Namibia could use in their teaching and learning to safeguard students' success in their academic life after graduation. Based on above, the Kirkpatrick's model was seen suitable by the researcher because in the nutshell the study evaluated the training program which was offered to education students that have graduated from the years 2011-2018 and see if the program was of good help. Substantively, the Kirkpatrick's model answers these with its first level which is 'reaction'. The first level of the model describes the level as a level of reaction which measures the result whether the education students reacted satisfactorily to the Bachelor Degree Honours training or they need some sought of intervention to help curb what was not addressed during training. 
Table 1: Overview of the Kirkpatrick four Levels of Evaluation

Table by Ulum (2015)

\begin{tabular}{cll} 
Level & \multicolumn{1}{c}{ Description } \\
\hline 1 & Reaction & $\begin{array}{l}\text { Sometimes referred to as happy or smile sheets, this level of evaluation } \\
\text { considers whether the participants reacted favourably to the training or } \\
\text { intervention. }\end{array}$ \\
\hline 2 & Learning & $\begin{array}{l}\text { Related to learning outcomes of the training or intervention, this level } \\
\text { considers whether the participants acquired the intended knowledge, } \\
\text { skills or attitudes based on their participation in the training or } \\
\text { intervention. }\end{array}$ \\
\hline 3 & Behaviour & $\begin{array}{l}\text { Sometimes referred to as 'transfer', this level considers the degree to } \\
\text { which the participants altered their subsequent behaviour in other } \\
\text { contexts (e.g. in the workplace) after participating in the training or } \\
\text { intervention. }\end{array}$ \\
\hline 4 & Results & $\begin{array}{l}\text { Sometimes referred to as organisational level evaluation, and related to } \\
\text { the longer term outcomes anticipated, this level considers whether the } \\
\text { overall aims have been achieved as a result of the interventions, and of } \\
\text { subsequent reinforcement. Rather than return on investment (ROI), the } \\
\text { fourth level refers to Return on Expectations (ROE). }\end{array}$ \\
\hline
\end{tabular}

\subsection{Research Problem}

Whilst a plethora of available literature has been written on paradigm shifts in teaching and learning at higher institutions of learning from an international and national perspective (Marwala, 2015; Penprase, 2018; Razah, Alkrash \& Sahboun, 2018; Schwab, 2017; Xing, 2017) not much is known about paradigm shifts in teaching and learning at the university of Namibia (Rundu Campus) that may help education graduants to excel ones they join the work force. The researcher considered this investigation to be of value, and that paradigm shifts in teaching and learning and implications should be understood from the education graduates in the years 2011-2018, inspectors, principals, head of departments and subject advisors' perspectives respectively because these are the stakeholders that are engaged with the students after training them at the university.

\subsection{Research Questions}

The following research questions were addressed in this study:

1. How can the University of Namibia redesign its curriculum to nature education graduants' success in life after graduation?

2. What challenges do education graduates encounter in the teaching profession after training?

3. What challenges are being experienced by superiors in schools where the graduates are recruited? 


\subsection{Significance of the Study}

This study is a contribution to the shift of the University of Namibia of curriculum transformation in terms of recurriculation in review of higher education industrial revolution 4.0. the findings of this study may impact the university positively, as it may inform them with challenges their graduates face after being trained, the way the graduates view the structure of the course outlines and the assessment techniques, what might seem to be changed and how the universities' stakeholders view their training pedagogy and deduce approaches which may help the university as they redesign their curriculum to help the graduants who are to join the workforce.

\section{Methodology}

\subsection{Research Design}

Qualitative methodology was compatible with the study's focus for as it enables researchers to dig deep into the phenomenon under study (Mpofu \& Chimhenga, 2016). Qualitative research allows for the collection of rich detail and insights into the participantsee experiences of the world and these may prove to be more meaningful than other approaches. A qualitative methodology for this study was suitable to evaluate the training course from the education graduates, principals, Heads of Departments, subject advisors and inspectors and deduce approaches that the University of Namibia may term inclusive in their redesigning of their curriculum to safeguard education students' success in the teaching profession.

\subsection{Population}

The population of this study consisted of education graduates from Unam's Rundu campus in the years 2011- 2018, inspectors, heads of departments, subject advisors and principals in the Kavango West Region of Namibia.

\subsection{Sample}

A purposive sample of twenty Bachelor Degree (Honours) graduates from Rundu Campus in the years 2011- 2018, three inspectors, three subject advisors, six Head of departments and six school principals from six selected schools in the Kavango West Region participated in the study. The purposive sampling was employed to select the sample size because purposive sampling is a sampling method that advocates using participants that are already known to have the information that the researcher is looking for. Substantively, purposive sampling is the deliberate choice of a participant due to the qualities the participant possesses (Etikan, Musa \& Alkassim, 2016). 


\subsection{Research Instruments}

Semi- structured interview guides were used to collect data. The semi- structured interview guides were two; this is because questions which were directed to the graduates were different from those which were directed to the HODs, principals, subject advisors and inspectors. Questions were different because the graduates were asked to evaluate the training course which was offered to them if it's doing any good to them in the teaching profession and the ones directed to the other participants focused on how they see the graduates that are teaching in their region and how they can help the university in redesigning its curriculum to ensure that the graduates produced from the university are fit for the workforce.

\subsection{Procedures}

After obtaining official access to the participants, arrangements were made to administer semi-structured interviews. The interviews provided opportunities for the participants to reflect on their experiences and evaluate the training program offered by the university. Semi-structured interviews were preferred for the collection of data as they enabled the researcher to probe responses and solicit further details from the interviewees.

\section{Ethical Considerations}

In order to maintain a climate of trust in the practice and outcomes of social research, an ethical assurance was established and was maintained by the participants. The aim and purpose of research was explained to the participants. Bryman (2012) has suggested four significant ethical considerations for researchers to avoid; namely, lack of informed consent; harm to participants; invasion of privacy; and deception. This research study has followed the core ethical issues of informed consent, confidentiality and anonymity, and minimizing harm to participants.

\section{Data Analysis}

The interview data from semi-structured interviews were categorized and thematic analysed.

\section{Results and Discussions}

To appropriately address the research questions posed in this study, the researcher presented the findings of the integrated interview data according to identified three thematic categories namely; challenges faced by graduates in the teaching profession, the latter training pedagogy of the university and curriculum change for the betterment of education students.

\subsection{Challenges faced by Unam's Rundu Campus graduates in the teaching profession}

It emerged from the analysis of data that education students face the following challenges ones they join the workforce: 
6.1.1 Lack of knowledge of the general job description, national standards, code of conduct for teachers and the public act

When asked to state the challenges students face in the teaching profession, they said that even if the students have knowledge about the general job description, the national standards, code of conduct and the public act, students are unable to execute what these documents entails. It is then empirical for the University of Namibia to ensure that these documents are thoroughly exposed to the students as soon as the students join the university so that they become part and parcel of their education journey while still at the university and if need be to conduct practicals on the national standards instruments rather than experiencing the practical part when they are already teachers.

\subsubsection{Compiling subject files}

When asked to state if the graduates have any idea of the subject files they supposed to keep. The results revealed that most of them if not all do not have any idea of what those files are and what content supposed to constitute each file. It was singled out and emphasized that these files are very important for any individual teacher because one file is meant to be an administration file that supposed to document important subject information and any other school-related information. Whereas the resource file documents the following: control Sheet, worksheets, projects, assignments, topic tasks, practical investigations, artifacts, including marking criteria, course material and workshop hand-outs and information on compensatory teaching in the subject. While the preparation file supposed to document the following: Control sheet, Table of contents, the teacher's personal time-table, Syllabus for all the subjects taught this year (the latest editions), Schemes of work for all the subjects taught that year (neatly typed) and Up-to-date daily/weekly written lesson preparation. The university is then advised to make this a priority as well so that students know what type of files to have and how they can compile them before they become teachers.

\subsubsection{Lack of classroom management}

When asked to state if the graduates know how to handle the class to ensure a successful lesson. Both participants were of the opinion that most of the education graduates do not know how to handle their learners in the classroom to ensure that teaching and learning is taking place smoothly. It appears to be that the university did not do enough to train the students holistically, that is to say not only in content delivery but also to make sure that the teaching and learning environment is favourable. One cannot teach learners that are noisy and learners cannot listen and grasp the content very well if there is too much noise in the classroom. A teacher is a manager of each classroom, thus if they lack knowledge on how to make the teaching and the learning environment favourable then teaching and learning will not take place or if it does, it occurs minimally. To concur with the above, (Dizdarevik, 2014) articulates that to be an efficient teacher means to know with what and how to motivate students to learn. Teacher as an efficient classroom manager needs to have skills to plan and prepare the education process, know how to organise the teaching and how to guide the class. Moreover, an efficient teacher needs to establish positive classroom climate and working discipline.

\subsubsection{Lack of mentorship}

It was revealed in the results that some mentor teachers that are assigned to the novice teachers are not doing enough to scaffold the teachers to get acquainted to the profession's expectations. As a result, the 
novice teachers do what they know and leave out what they seem to struggle with. To mitigate this, the University of Namibia should ensure that their students are well trained before they are termed graduates. The theory part seems not to help in any case. Mentoring involves guidance and suggestion, as well as the development of autonomous skills, judgments, personal and professional mastership, expertise, trust and the development of self-confidence over time. Mpofu and Chimhenga (2016) are of the opinion that mentoring plays an important role in enhancing novice teachers opportunities to learn within the contexts of teaching. Mentoring in specific context not only allows student teachers to acquire context specific knowledge but also develop situation-based skills, which can be transferred to similar future situations in that context.

\subsubsection{Lack of content in lesson delivery}

When asked to state if they are able to deliver their subject content at ease. The responses were that those placed in pare with what they have majored in during training are doing well with their content delivery but those that are placed at the junior and senior secondary phase are getting it hard to deliver the subject content. It was then suggested that it will do all stakeholders well if the University of Namibia, specifically Rundu Campus change the intake of lower primary and upper primary to junior and senior secondary phase. This is because in the past years until now the University has over supplied schools with lower and upper primary phase teachers while the junior and senior secondary phase is in dividing line.

\subsection{The latter training pedagogy at the University of Namibia}

It was singled out that the training pedagogy that the University of Namibia is implementing is questionable. This is because students spend four years at the university to train them to become professionals, but in the end results do not recon the value of the four years spent. It is worth noting that the University of Namibia is too theoretical that pragmatic. It was confirmed that students are saturated with information about the modules offered at Unam and use the content to pass examinations and excel to the next level until they graduate.

When asked to comment if they are able to use the content to explain it to the next person. The majority said that they are unable to.

The other issue is about the assessment strategies. It was suggested that it may be wise if the university will refrain from giving group assignments and tests that accord recalling of information than having test, assignment and examination questions that allow them to practice about the real classroom experiences. Asking students what reading is, is not enough, but asking them how to teach reading to a special learner is very important. Currently, the type of questioning strategies that most academics are using does not allow students to practice the knowledge gained but rather reproduce what was taught during lectures.

\subsection{Curriculum change for the betterment of education students}

When asked to state how the university's curriculum could change to ensure successful education students prior to joining the work force. The respondents said that the university should liaise with school (Ministry of Education) syllabus to ensure that what they offer in their various courses is what the schools require the teachers to exhibit. Furthermore, there is a need for the university to visit schools and listen to what their 
needs are and redesign their curriculum as such. To extend a point, it was said that the university's curriculum should make provisions to expose their students to classroom environments in their first year. School Based students should start in year one (1). It was still said that micro-teaching should start in year one so that as students progresses they are only corrected until they get it right. The university's curriculum should also be designed in such a way that more contact hours are reserved for practicals than theory. Students need to practice what they are taught. This calls for effective student-centered approach implementation.

\section{Conclusions and Recommendations}

This qualitative study sought to evaluate the education training programme of the University of Namibia at Rundu Campus about the paradigm shifts in teaching and learning. The study concludes that there are five challenges that education graduates experience as they join the teaching profession. These challenges include, knowledge of the general job description, national standards, code of conduct for teachers and the public act, compiling subject files, classroom management, mentorship and content in lesson delivery. It was also concluded that the university should shift to the following to ensure that they produce graduates that are fit for the workforce: The University's curriculum should also be redesigned in such a way that more contact hours are reserved for practicals than theory. Students need to practice what they are told. This calls for studentcentered approach. The questioning strategies in tests, assignments and examinations should be changed to pragmatics. The university should liaise with school (Ministry of Education) syllabus to ensure that what they offer in their various courses is what the schools need the teachers to exhibit. Moreover, there is a need for the university to visit schools and listen to what their needs are and redesign their curriculum as such, expose education students to classroom environments in their first year, School Based Studies and micro- teaching should start in year one (1).

Additionally, Rundu Campus to change the intake of Junior Primary and Senior Primary to Junior and Senior Secondary phase. The university is again advised to teach students what type of subject files to have and how they can compile them before they become teachers. It is also worth noting that having the subject content is not enough for a successful lesson, thus the university should redesign its curriculum in such a way that it incorporates teaching students how to manage classrooms. It is also concluded that the University of Namibia should avail and teach explicitly the National Standards for Teachers in Namibia, code of conduct for teachers, general job descriptions for teachers and the public act right in year one.

\section{References}

Abdulghani, H. M., Shaik, S. A., Khamis, N., Al-Drees, A. A., Irshad, M., Khalil, M. S., \& Isnani, A. (2014). Research methodology workshops evaluation using the Kirkpatrick's model: translating theory into practice. Medical Teacher, 36(1), pp.24-29.

Alliger, G. M., Tannenbaum, S.I., Bennett, W., Traver, H. \& Shotland, A. (1997). A meta-analysis of the relations among training criteria. Personnel Psychology, 50(2), 341- 358. http://dx.doi.org/10.1111/j.1744-6570.1997.tb00911.x

Bryman, A. (2012). Social research methods (4th ed). Oxford, New York:Oxford University Press.

Chang, N., \& Chen, L. (2014). Evaluating the learning effectiveness of an online information literacy class based on the Kirkpatrick framework. Libri, 64(3), 211-223. http://dx.doi.org/10.1515/libri-2014-0016 
Cohen, L., Manion, L., \& Morrison, K. (2011). Research methods in education (7th ed). New York, NY: Routledge.

Dizdarevik, J., D. (2014). Classroom Management. International Journal of Cognitive Research in Science, Engineering and Education, (2)1, pp. 51-56.

Etikan, I., Sulaiman, A. M. \& Rukayya, S., A. (2016). Comparison of Convenience Sampling and Purposive Sampling. American Journal of Theoretical and Applied Statistics 2016, 5(1), PP.1-4.

Holton, E.F. (1996). The flawed four-level evaluation model. Human Resource Development Quarterly, 7(1),

5-21. http://dx.doi.org/10.1002/hrdq.3920070103

Kirkpatrick, D.L. (1998). Another look at evaluating cop.icfwebservices.com/ training programs. Alexandria, VA: American Society for Training \& Development.

Kirkpatrick, J. \& Kayser-Kirkpatrick, W. (2014). The Kirkpatrick four levels: A fresh look after 55 years. Ocean City: Kirkpatrick Partners.

Marwala, T. (2015). Causality, correlation and artificial intelligence for rational decision making. 5 Toh Tuck Link, Singapore 596224: World Scientific Publishing.

Mpofu, J. \& Chimhenga, S. (2016). The Importance of Mentoring: Findings from Students Doing Post Graduate Diploma in Education at Zimbabwe Open University, Bulawayo Region. Journal of Research \& Method in Education, 6(3), pp.27-31.

Penprase, B. E. (2018). The fourth industrial revolution and higher education. In N. W. Gleason, Higher education in the era of the fourth industrial revolution. Singapore: Palgrave Macmillan.

Praslova, L. (2010). Adaptation of Kirkpatrick's four level model of training criteria to assessment of learning outcomes and program evaluation in higher education. Educational Assessment, Evaluation and Accountability, 22(3), 215-225. http://dx.doi.org/10.1007/s11092-010-9098-7

Razah, N.A., Alakrash, H. \& Sahboun, Y. (2018). English Language Teachers' Readiness for the Application of Technology towards Fourth Industrial Revolution Demands. Asia-Pacific Journal of Information Technology and Multimedia, 7(2), PP. 89-98.

Saks, A. M. \& Haccoun, R. R. (2010). Managing performance through training and development. Toronto: Nelson.

Schwab, K. (2017). The fourth industrial revolution (1st ed.). New York: Crown Business.

Ulum, O., G. (2015). Program Evaluation through Kirkpatrick’s Framework. Pacific Business Review International, 8(1), pp. 106-111.

Xing, B. (2017). "Visible light based throughput downlink connectivity for the cognitive radio networks," in Spectrum Access and Management for Cognitive Radio Networks. Singapore: Springer Science +Business Media.

Yardley, S. \& Dornan, T. (2012). Kirkpatrick's levels and education 'evidence'. Medical Education, 46(1), 97-106. http://dx.doi.org/10.1111/j.1365-2923.2011.04076.x 